\title{
MAGNETIC PROPERTIES OF IRON-BASED AMORPHOUS AND NANOCRYSTALLINE Fe-Zr-X-B (X: Cu, Al) ALLOY FILMS
}

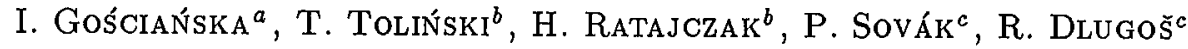 \\ AND M. KONC̆ ${ }^{c}$
}

anstitute of Physics, A. Mickiewicz University, Umultowska 85, 61-614 Poznań, Poland ${ }^{b}$ Institute of Molecular Physics, Polish Academy of Sciences Smoluchowskiego 17, 60-179 Poznań, Poland

${ }^{c}$ Department of Experimental Physics, P.J. Safarik University, Košice, Slovakia

Thermal stability and magnetic properties of thin films, of a few Fe-based amorphous and nanocrystalline alloys, have been studied. The alloys belong to the class $\mathrm{Fe}-\mathrm{M}-\mathrm{B}$, whose representatives are: $\mathrm{Fe}_{87} \mathrm{Zr}_{4} \mathrm{Cu}_{1} \mathrm{~B}_{8}, \mathrm{Fe}_{87} \mathrm{Zr}_{7} \mathrm{~B}_{6}$, and $\mathrm{Fe}_{87} \mathrm{Zr}_{7} \mathrm{Al}_{1} \mathrm{~B}_{5}$ and are of particular interest because of their wide variety of magnetic properties. The films were prepared by flash evaporation onto liquid nitrogen cooled substrates. Measurements of the Kerr effect, the Hall effect, and ferromagnetic resonance in the films were carried out as functions of the annealing temperature. It was found that the changes in the coercive field $H_{c}$, resonance linewidth $\Delta H_{p p}$, effective magnetization $M_{\text {eff }}$, Hall parameters, and resistance were correlated with the structural changes in the studied films.

PACS numbers: 73.61.Tm, 75.50.Bb

\section{Introduction}

Nanocrystalline and amorphous materials are still widely investigated due to their possible applications based on their soft magnetic properties $[1,2]$ and the giant magneto-impedance effect [3]. In this paper we continue our studies of structural and magnetic properties of thin nanocrystalline films which belong to the $\mathrm{Fe}-\mathrm{M}-\mathrm{B}$ alloy series. The thermal stability of $\mathrm{Fe}_{87} \mathrm{Zr}_{4} \mathrm{Cu}_{1} \mathrm{~B}_{8}, \mathrm{Fe}_{87} \mathrm{Zr}_{7} \mathrm{~B}_{6}$, and $\mathrm{Fe}_{87} \mathrm{Zr}_{7} \mathrm{Al}_{1} \mathrm{~B}_{5}$ films is verified. Similar systems were previously investigated using ferromagnetic resonance and Mössbauer techniques [2]. Especially, the ferromagnetic resonance appeared to be a sensitive indicator of the crystallization process. 


\section{Experimental}

The thin films were prepared by flash evaporation of pulverized alloys onto liquid nitrogen cooled glass substrates in the vacuum of $1.5 \times 10^{-9}$ Torr [4]. The thickness of the samples was determined using the multibeam interference method and was kept at about $30 \mathrm{~nm}$ with the accuracy of $20 \%$. The magnetic parameters, namely the coercive field $H_{\mathrm{c}}$, magnetic induction $B_{\mathrm{S}}$, spontaneous Hall coefficient $R_{\mathrm{S}}$, effective magnetization $M_{\mathrm{eff}}$, and resonance linewidth $\Delta H_{p p}$ for annealing temperatures $T_{\mathrm{a}}=623,723,773$, and $823 \mathrm{~K}$ were obtained from the measurements of magnetooptical Kerr effect (MOKE), spontaneous Hall effect (SHE), and ferromagnetic resonance (FMR), respectively. Annealing temperatures $T_{\mathrm{a}}$ were extracted from the temperature dependence of resistivity $\rho(T)$. The evolution of the films structure was observed by the transmission electron microscopy (TEM). The ferromagnetic resonance was carried out at the frequency of $18.74 \mathrm{GHz}$ at a room temperature. The effective magnetization is defined as $M_{\text {eff }}=M_{\mathrm{S}}-\mu_{0} H_{u}$, where $H_{u}$ is the perpendicular anisotropy field $\left(2 K_{u} / M_{\mathrm{S}}\right)$.

\section{Results and discussion}

Figure 1 shows an example of the TEM images of $\mathrm{Fe}_{87} \mathrm{Zr}_{7} \mathrm{~B}_{6}$ alloy for some temperatures $T_{\mathbf{a}}$. It is seen that already in the as-deposited state the sample is partly nanocrystalline with the grains diameter of about $15 \mathrm{~nm}$. The diameter rises to about $50 \mathrm{~nm}$ at the highest $T_{\mathrm{a}}$.

The development of the crystallization process is confirmed by the temperature dependence of the resistivity (Fig. 2). The above changes in the structure of the films correlate with the behavior of the magnetic properties performed in Figs. 3. and 4. For $\mathrm{Fe}_{87} \mathrm{Zr}_{7} \mathrm{~B}_{6}$ and $\mathrm{Fe}_{87} \mathrm{Zr}_{7} \mathrm{Al}_{1} \mathrm{~B}_{5}$ films both field the coercive $H_{\mathrm{c}}$

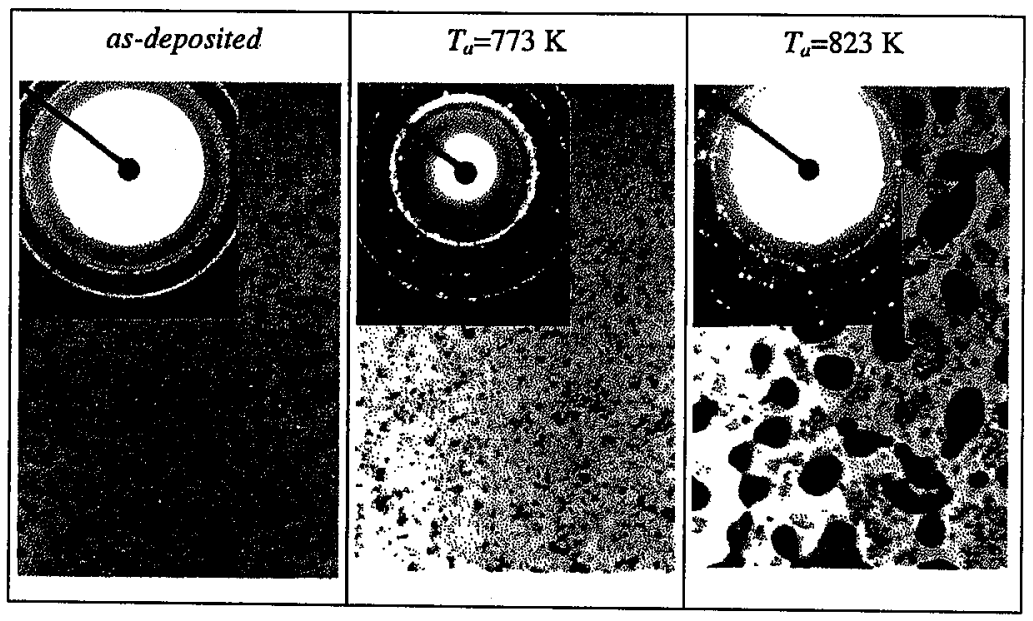

Fig. 1. Example of TEM images for the $\mathrm{Fe}_{87} \mathrm{Zr}_{7} \mathrm{~B}_{6}$ alloy film (magnification about $22000 x)$. 


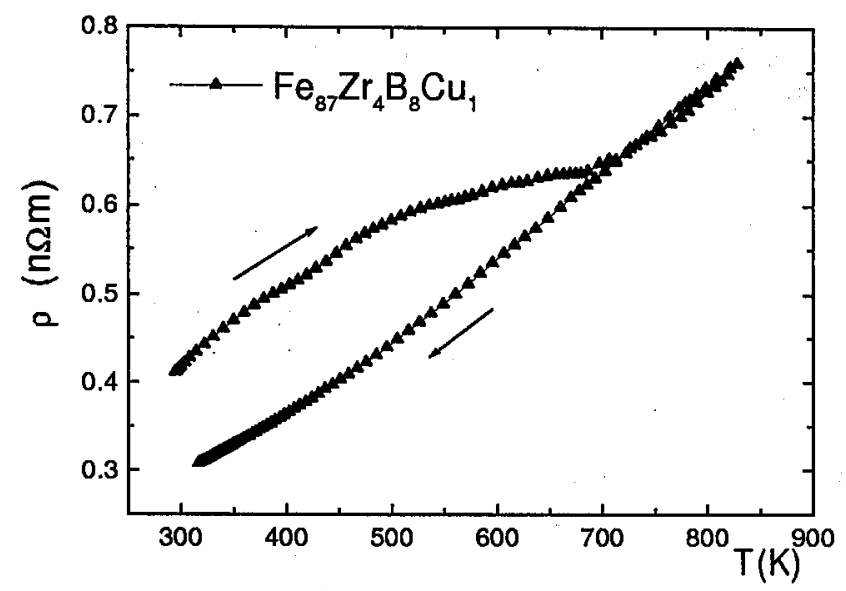

Fig. 2. Resistivity $\rho(T)$ measured with the rate of temperature change $5^{\circ} / \mathrm{min}$.
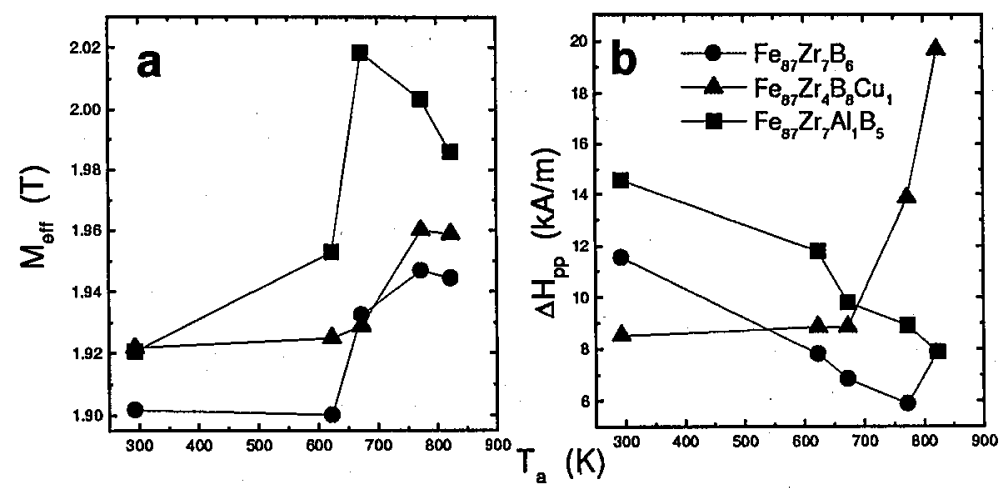

Fig. 3. Effective magnetization $M_{\text {eff }}$ (a) and resonance linewidth $\Delta H_{p p}$ (b) as a function of annealing temperature $T_{\mathrm{a}}$.

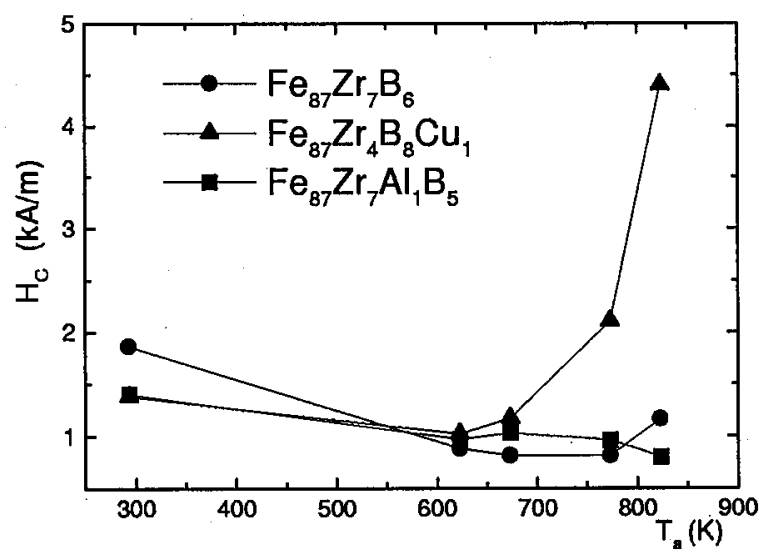

Fig. 4. Coercive field $H_{\mathrm{c}}$ as a function of annealing temperature $T_{\mathrm{a}}$. 
and the resonance linewidth $\Delta H_{p p}$ decrease with increasing temperature and eventually have a flat minimum near $700 \mathrm{~K}$. This is a result of the annealing induced enlargement of the grains either by merging of the nanocrystallites or by the proceeding crystallization of the amorphous matrix. The contribution of the surface anisotropy to the crystalline anisotropy is less significant when the grains become larger. In the case of the $\mathrm{Fe}_{87} \mathrm{Zr}_{4} \mathrm{Cu}_{1} \mathrm{~B}_{8}$ alloy $H_{\mathrm{c}}$ and $\Delta H_{p p}$ are approximately constant up to $600 \mathrm{~K}$ and increase above that temperature. The discrepancy in comparison with the previous samples can result from the different course of the crystallization, however the role of copper is not clear yet. The effective magnetization $M_{\text {eff }}$ increases slightly above $T_{\mathrm{a}}=623 \mathrm{~K}$ for all samples.

The Hall coefficient $R_{\mathrm{S}}$ decreases with temperature for all samples. The magnetic induction $B_{\mathrm{S}}$ obtained from MOKE measurements changes from $1.8 \mathrm{~T}$ in an as-deposited state to $1.97 \mathrm{~T}$ after annealing at $823 \mathrm{~K}$ for $\mathrm{Fe}_{87} \mathrm{Zr}_{7} \mathrm{~B}_{6}$ and from $1.76 \mathrm{~T}$ to $1.88 \mathrm{~T}$ for $\mathrm{Fe}_{87} \mathrm{Zr}_{4} \mathrm{Cu}_{1} \mathrm{~B}_{8}$.

\section{Conclusions}

The $\mathrm{Fe}_{87} \mathrm{Zr}_{7} \mathrm{~B}_{6}$ and $\mathrm{Fe}_{87} \mathrm{Zr}_{7} \mathrm{Al}_{1} \mathrm{~B}_{5}$ alloy films appeared to be thermally more stable than $\mathrm{Fe}_{87} \mathrm{Zr}_{4} \mathrm{Cu}_{1} \mathrm{~B}_{8}$ in the considered temperature range, i.e. they better conserve the soft magnetic properties. The nanocrystalline structure observed at the as-deposited state is present up to $700 \mathrm{~K}$, only the dimensions of the grains slightly change in this range.

\section{References}

[1] K. Suzuki, G. Herzer, J.M. Cadogan, J. Magn. Magn. Mater. 177-181, 949 (1998).

[2] D.S. Schmool, J.S. Garitaonandia, P. Gorria, J.M. Barandiarán, J. Magn. Magn. Mater. 177-181, 955 (1998).

[3] L.V. Panina, K. Mohri, K. Bushida, M. Noda, J. Appl. Phys. 76, 6198 (1994).

[4] I. Gościańska, H. Ratajczak, M. Urbaniak, P. Sovák, A. Zorkovská, P. Matta, M. Konč, J. Phys. IV (France) 8, 233 (1998). 